\title{
FVDZ-Bundesvorsitzender Harald Schrader wird 60
}

\author{
Als Harald Schrader vor knapp fünf Monaten zum Bundesvorsitzenden des Freien Verbandes Deutscher \\ Zahnärzte gewählt wurde, ist dies ganz ohne großes Feuerwerk passiert. Er freute sich, er dankte für das \\ Vertrauen - und dann ging es geschäftsmäßig, ruhig und abgeklärt zur Sache. Am 9. März feiert Schrader \\ seinen 60 Geburtstag, als Bundesvorsitzender legt er erst richtig los.
}

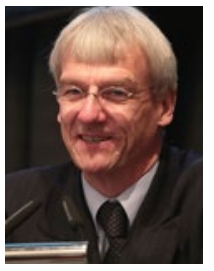

Das große Brimborium ist Schraders Sache nicht, als Nordlicht qua Geburt bedient Schrader so ziemlich alle Adjektive, mit denen die Menschen aus dem Norden gemeinhin belegt werden: Zurückhaltend, unprätentiös und zupackend - all das stimmt für den FVDZ-Bundesvorsitzenden. Sturmfest und erdverwachsen, wie es im Niedersachsenlied heißt, und was sicher auch für den Wahl-Schleswig-Holsteiner gilt.

Zur Welt kam er nämlich im niedersächsischen Fredenbeck bei Stade im Alten Land. Der Vater leitete dort die Raiffeisenbank und gründete später eine Konservenfabrik. Das Kollegium der Schule behagte dem Junior aber anscheinend nicht so sehr (oder war es umgekehrt?). Also kam der Junge auf's Internat - genauer gesagt auf das Internatsgymnasium Pädagogium Bad Sachsa im Harz, wo er die Reifeprüfung ablegte.

\section{Zahnarzt auf Umwegen}

Nach dem Wehrdienst wollte Schrader zunächst Volkswirt werden. Aber trockene Zahlen waren dann wohl nicht so recht nach seinem Geschmack. Jedenfalls ging ihm eines Tages auf der Heimfahrt von Freiburg in Höhe Göttingen der Sprit aus. Die Zwangspause nutzte er, um bei Freunden in der Universitätsstadt einzukehren. Der Vater des besten Schulfreundes war Zahnarzt, Haralds älterer Bruder studierte bereits Zahnmedizin, und so bewarb er sich kurz entschlossen in Göttingen. Die Assistenzzeit absolvierte Schrader in Ostfriesland, dann wechselte er das Bundesland und ließ sich im Sachsenwald in Schwarzenbeck östlich von Hamburg nieder.
Dort begann das standespolitische Engagement des heutigen FVDZ-Bundesvorsitzenden in den 1980er Jahren in der Schleswig-Holsteinischen Bezirksgruppe Süd des Freien Verbandes. Wer da mithalten wollte, musste nicht nur fit im Kopf sein, er musste auch Sitzfleisch mitbringen. Direktabrechnung, Kostenerstattung, Dualer Weg und dann schließlich „der Korb“ - das alles waren schon damals die standespolitischen Themen, an denen sich die Zahnärzte die Köpfe heiß redeten.

\section{Erst denken, dann reden...}

...so läuft das bei Schrader. Emotionen waren und sind nicht ohne weiteres auszumachen. Sein Herz trägt er nicht unbedingt auf der Zunge, wohl aber hat er feste Wertvorstellungen.

Schrader meckert nicht, er packt an und übernimmt Verantwortung, zuerst im Kreisverein und der Bezirksgruppe, später auf Landes- und Bundesebene des Freien Verbandes als Versammlungsleiter, bis er sich schließlich zur Wahl als Bundesvorsitzender stellte. Ungeachtet dessen hatte er diverse andere Ämter als KZV- und als Kammerdelegierter, als Gutachter, Obergutachter und Vorsitzender des Prothetik-Einigungsausschusses, als Mitglied in vielen weiteren Ausschüssen von Kammer und KZV und als Richter am Landessozialgericht.

Franz Müntefering hat seinen Job als SPD-Vorsitzender mal als „schönstes Amt nach'm Papst“ bezeichnet. Ob das auch für Schrader so sein wird, ist noch offen. Der FVDZ-Bundesvorsitz gehört jedenfalls zu einer der schwierigsten und zugleich spannendsten Aufgaben, die ein Zahnarzt ehrenamtlich zu bewältigen hat. Der Freie Verband wünscht dafür eine glückliche Hand. Happy Birthday zum Sechzigsten, lieber Harald Schrader.

\section{Ex-Bundesdatenschutzbeauftragter ist jetzt Schlichter}

Die Gesellschaft für Telematikanwendungen der Gesundheitskarte, gematik, hat den früheren Bundesdatenschutzbeauftragten Peter Schaar zum 1. Januar 2016 zum Vorsitzenden der Schlichtungsstelle ernannt. In dieser Funktion wird Schaar „die Entscheidungen über Regelungen, Aufbau und Betrieb der Telematikinfrastruktur voranbringen“, heißt es in einer Pressemitteilung.

Die gematik-Schlichtungsstelle gibt es seit 2010. Das im Dezember 2015 verabschiedete E-Health-Gesetz hatte die Aufga- ben der Schlichtungsstelle erweitert. Demnach soll die Schlichtungsstelle nicht nur bei Streitfragen über den Aufbau der Infrastruktur zuständig sein, sondern kann auch im laufenden Betrieb hinzugezogen werden.

Schaar gilt als Experte in Sachen Datenschutz. Er war von 2003 bis 2013 der Bundesbeauftragte für den Datenschutz und die Informationsfreiheit. Heute ist er auch als Vorsitzender der Europäischen Akademie für Informationsfreiheit und Datenschutz tätig. cas 